\title{
Carcinoma ex pleomorphic adenoma of the parotid gland with cardiac metastasis
}

\author{
Anuja Bhandari ${ }^{1}$, Shovana Karki ${ }^{1}$, Geeta Sayami ${ }^{1}$ \\ ${ }^{I}$ Department of pathology, Institute of Medicine, Tribhuvan University Teaching hospital, Kathmandu, Nepal
}

\author{
Keywords: \\ Carcinoma; \\ Cardiac; \\ Ex pleomorphic adenoma; \\ Metastasis; \\ Parotid; \\ Tumor;
}

\begin{abstract}
Pleomorphic adenomas are the most common neoplasms of the major salivary glands. They are also known as benign mixed tumors because of the presence of both epithelial and mesenchymal elements. In parotid gland, approximately $65 \%-75 \%$ of tumors are pleomorphic adenomas. In parotid gland, usually it occur lateral to the plane of facial nerve. They present in middle aged patients as well defined, solitary, painless mass and are slow growing tumors. Few subset of tumors may undergo malignant transformation. Carcinoma ex pleomorphic adenoma is a rare and aggressive malignancy that arises from primary or recurrent pleomorphic adenoma. It occurs in $6 \%$ of all pleomorphic adenomas. Diagnosis of malignancy and treatment is largely based on pathologic and radiographic features. Distant metastases have been reported mainly in the lung. . We present an unusual case of $68 \mathrm{yrs}$ female patient with carcinoma ex pleomorphic adenoma of the parotid gland with cardiac metastasis.
\end{abstract}

\section{Correspondence:}

Dr. Shovana Karki, MD

(c) (i)

Lecturer, Department of pathology,

Institute of Medicine, Tribhuvan University Teaching hospital,

Kathmandu, Nepal

ORCID ID: 0000-0001-5429-2422

Email: shovana_karki@hotmail.com

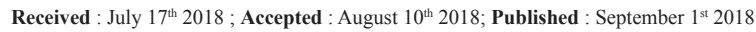

Citation: Bhandari A, Karki S, Sayami. Carcinoma ex pleomorphic adenoma of the parotid gland with cardiac metastasis. J Pathol Nep 2018;8;1422-24. DOI: 10.3126/jpn.v\%vi\%i.20899

Copyright: This is an open-access article distributed under the terms of the Creative Commons Attribution 4.0 International License, which permits unrestricted use, distribution, and reproduction in any medium, provided the original author and source are credited.

\section{INTRODUCTION}

Pleomorphic adenoma is the most common benign salivary gland tumor. Three components are seen in varying quantities and histologies i.e. epithelial, myoepithelial, and mesenchymal components. In approximately $80 \%$ cases, it is found in parotid gland and is more common in women. Malignant transformation into carcinoma ex pleomorphic adenoma (CAEXPA) is seen in approximately $6 \%$ of these tumors and it is also known as mixed malignant tumor. ${ }^{1}$

CAEXPA accounts for approximately $11.6 \%$ of all malignant neoplasms and $3.6 \%$ of all salivary gland neoplasms. It usually develops in the sixth and seventh decades of life. Sudden enlargement at the site may be the first symptom noticed by the patient. If the tumor extends into surrounding structures including soft tissues, facial nerve, and jaw, patient may complain of facial pain, paralysis, and dental pain respectively. The risk of malignant transformation is increased with increased preoperative duration of pleomorphic adenoma. ${ }^{2,4}$ 


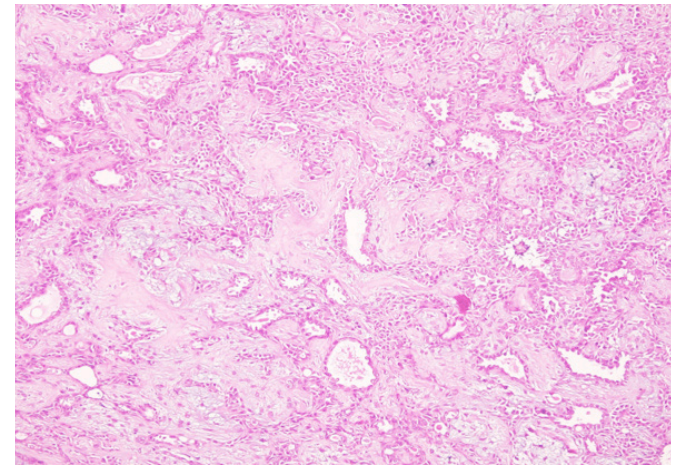

Figure 1: Photomicrograph showing biphasic population of epithelial and mesenchymal cells with chondromyxoid stroma(HE stain; X50).

\section{CASE REPORT}

A 68-year-old female patient reported with a complaint of swelling on the right side of the face since childhood which increased in size for last six months. On CT scan, a mass was also found incidentally on right atrium. Right parotidectomy was performed. The biopsy specimen was sent to histopathology laboratory. Grossly, two pieces of grey-white tissue was received from right parotid gland, largermeasured $8 \times 7 \times 4 \mathrm{~cm}$. The cut section showed well encapsulated mass with solid as well as cystic areas filled with myxoid and hemorrhagic material.

Simultaneously, excision biopsy of the right atrial mass was performed and sent to histopathology laboratory. The mass from right atrium was in single piece and measured $9 \times 6 \times 1.5$ $\mathrm{cm}$. Cut sections showed solid glistening areas.

Microscopically, sections from right parotid showed well circumscribed capsulated mass composed of multiple lobules of tumor cells consisting of benign areas which showed epithelial and mesenchymal component. Epithelial component consisted of tubules, nests and cords lined by cuboidal cells and surrounding multiple layers of myoepithelial cells with eccentric nuclei and vacuolated cytoplasm. Stroma showed chondromyxoid material (fig. 1). Focally, nests of atypical cells were seen with high N:C ratio, vesicular chromatin and small prominent nucleoli. Perineural and lympho-vascular invasions were noted. Areas of necrosis and hyalinization were seen (fig. 2). Sections from the atrial mass showed areas of necrosis and hemorrhage with proliferation of atypical cells with similar morphology as described above (Fig. 3). On immunohistochemistry, cells in the malignant areas were positive for S 100. Cell lining the tubules were cytokeratin positive.

\section{DISCUSSION}

Pleomorphic adenoma are usually benign and if left untreated, about $25 \%$ of pleomorphic adenomas can undergo

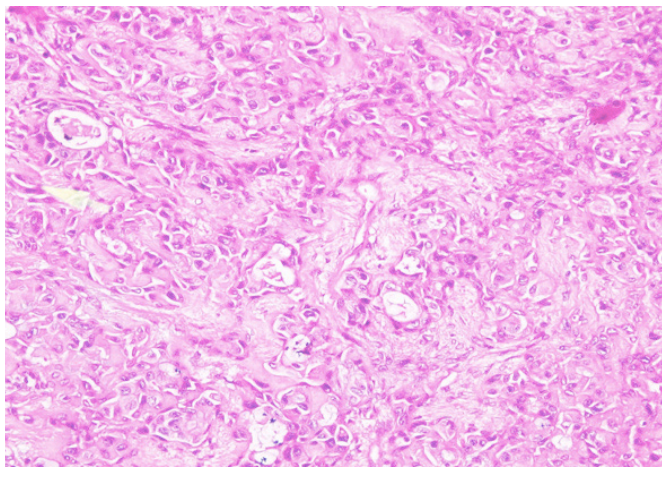

Figure 2: Photograph showing nests of atypical cells with high N:C ratio, vesicular chromatin and prominent nucleoli(HE stain; X100).

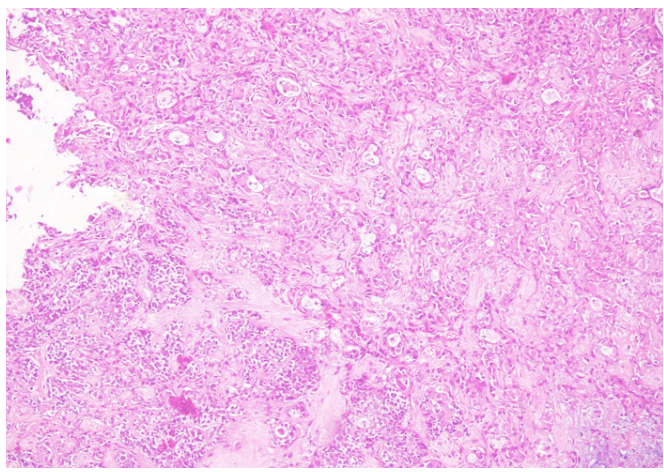

Figure 3: Photograph from atrial mass showing atypical cells with high $N$ : C ratio (HE stain; X50).

malignant transformation. ${ }^{3}$ Carcinoma ex pleomorphic adenoma arises from a primary or recurrent benign pleomorphic adenoma. ${ }^{4}$ Usually patient have long history of pleomorphic adenoma and they present with rapid increase in size, pain or facial nerve involvement. ${ }^{3}$ It most commonly present as a firm mass in the parotid gland. It accounts for approximately $3.6 \%$ of all salivary gland neoplasms. ${ }^{5}$

CAEXPA is defined as a pleomorphic adenoma in which an epithelial malignancy is present. Epithelial malignancy seen in most of the cases is adenocarcinoma (not otherwise specified). Other malignancy such as mucoepidermoid carcinoma, squamous cell carcinoma, adenosquamous cell carcinoma, adenoid cystic carcinoma, epithelial myoepithelial carcinoma, sarcomatoid carcinoma, acinic cell carcinoma, clear cell carcinoma and myoepithelial carcinoma have also been reported. ${ }^{2}$ CXPA is seen most commonly in parotid gland. It may also occur in submandibular gland, minor salivary glands and palate. ${ }^{4}$ Grossly, size of CAEXPA ranges from $1 \mathrm{~cm}$ to $20 \mathrm{~cm}$. Grossly, clearly invasive process can be seen occasionally associated with a well-circumscribed pleomorphic adenoma. Minimally invasive tumors can be completely encapsulated. Necrosis and hemorrhage can also be present. ${ }^{5}$ 
Uncircumbscribed infiltrative margins are seen in cases of infiltrative CAEXPA. Good prognosis is seen with infiltration of capsule till $8 \mathrm{~mm}$. Peri-neural and perivascular invasion, necrosis and hemorrhages are also seen. Noninvasive CAEXPA are well circumbscribed. Benign part is rarely seen. Peripheral area or subcapsular area shows increased mitotic activity. Irregular outline is seen in luminal and non-luminal cells. Hyalinized stroma and acellular stroma is also evident. ${ }^{4}$

It spreads mainly through direct extension, through lymphatic vessels, and rarely hematogenously. ${ }^{6}$ Local or distant metastases are seen in upto $70 \%$ of cases. Lung, bone especially spine, abdomen and central nervous system are the most common metastatic site in order of frequency.

Pleomorphic adenoma also metastasizes to different parts of the body mainly through hematogenous route. Incomplete enucleation of the pleomorphic adenoma during surgery may lead to recurrence and vascular implantation may occur. Parotid gland is the most common site of primary tumor followed by submaxillary gland, palate and the minor salivary glands. Bone, lung and lymph nodes are the most common site of metastases. Other sites of metastases found are in liver and supraspinatus muscle. ${ }^{7}$

Our case demonstrates a rare case of carcinoma expleomorphic adenoma with cardiac metastasis. To our knowledge, this case is exceptional as cardiac metastasis of carcinoma ex pleomorphic adenoma has not been previously reported. Every case of pleomorphic adenoma should be regarded as a premalignant condition and treated with appropriate surgery as there is significant risk of malignant conversion. ${ }^{8}$

\section{CONCLUSION}

Pleomorphic adenomas are classified as benign tumors but have wide range of biologic behaviours. As they can undergo malignant transformation and metastasize, and carry significant morbidity and mortality, they should be treated aggressively with appropriate surgery.

\section{Conflict of Interest: None}

\section{REFERENCES}

1. Chooback N, SHen Y, Jones M, et al. Carcinoma ex pleomorphic adenoma: case report and options for systemic therapy. Curr Oncol. 2017;24:e251-4. Crossref

2. Sload RL, Carbone P, Johnson C, Johnson T. Carcinoma ex pleomorphic adenoma of the parotid gland. ActaOtoLaryngologica Case Reports 2016;1:67-70. $\underline{\text { Crossref }}$
3. Kato H, Kanematsu M, Mizuta K, Ito Y, Hirose Y. Carcinoma ex pleomorphic adenoma of the parotid gland: radiologic-pathologic correlation with MR imaging including diffusion- weighted imaging. Am J Neuroradiol 2008;29:865-7. Crossref

4. Buva KB, Deshmukh AA, Deshmukh AA. A case report of rare carcinoma ex pleomorphic adenoma of submandibular gland and its detailed description. J Clin Diagn Res 2017;11:ZD15-7. Crossref

5. Dhillon M, Tomar D, Sharma M, Goel S, Srivastava S. Carcinoma ex pleomorphic adenoma of parotid gland with hepatic metastasis: clinic-radiological case report. J Clin Diagn Res 2014;8:QD04-6. Crossref

6. Rossi L, Giordani E, Fontana A, et al. An unusual case of spleen metastasis from carcinoma ex pleomorphic adenoma of the parotid gland. World J Surg Oncol. 2014;12:18. Crossref

7. Soltedo J, Aranaga N. Metastasizing pleomorphic adenoma of the parotid gland. Javier Ecancer medical science. 2017; 11:758.

8. Sheedy SP1, Welker KM, DeLone DR, Gilbertson JR. CNS metastases of carcinoma ex pleomorphic adenoma of the parotid gland. AJNR Am J Neuroradiol. 2006;27:1483-5. Crossref 